\title{
Global sea level change: Determination and interpretation
}

\author{
Bruce C. Douglas \\ NOAA, National Oceanographic Data Center, Washington, D.C.
}

\section{Introduction}

The notion of sea level rise brings to the popular mind the specter of deep inundation of coastal regions. One pictures skyscrapers emerging from the waters like so many sleeping flamingos standing in the shallows of a lake. Of course if all of the world's ice sheets suddenly melted or collapsed, this vision would apply to New York City and its coastal counterparts. But there is a general consensus that such a calamity is not an immediate threat [Houghton et al., 1990]. The actual situation for the recent historical past and near future appears to be more benign, but with nonetheless extremely significant, even devastating impacts due to erosion and flooding of coastal areas.

Controversy concerning the significance of the present rate of global sea level rise, and how it may relate to whether the "greenhouse" is here or not, is very much in the public sphere (for a few prominent examples see Cory, [1991]; Chui, [1991]). Although the present (meaning the average over the last 100 years or so) rate of rise and its interpretation is subject to a certain amount of disagreement, it is an observed fact that relative sea level is rising in most coastal regions and causing major problems just at the time when rapid coastal development is taking place. If the postulated global warming and associated greatly increased rate of sea level rise occur in the next century, these problems will be exacerbated.

Many important books [Pugh, 1987; National Research Council (NRC), 1990; Emery and Aubrey, 1991; Woodworth et al., 1992; Warrick et al., 1993; Bird, 1993] and comprehensive reviews [e.g., Woodworth, 1993; Baker, 1993; Gornitz, 1993, 1994] on the subject of sea level have appeared in recent years. These can be consulted for an exhaustive list of references dealing with sea level rise estimates, and matters involving tidal analyses, measuring sea level, data analysis, and impacts. It is not the purpose of this paper to imitate these reviews, nor the ones cited later concerning such diverse subjects as coastal geomorphology, or how sea level rise is related to climate change. The volumes and papers mentioned above, as well as many of those referenced later, will of necessity find their way into the library of anyone deeply interested in the sea level problem.

Rather, what is intended is (at the request of the editors) to assemble from the many available books, reviews, and papers a view of where the field of sea level research stands today and how further progress can be made. Especially it is desired for this paper to serve as a resource for the non-specialist. This last goal reflects the fact that the study of sea level is interdisciplinary, involving oceanography, geophysics, meteorology, geology, geodesy, coastal geomorphology, and other related and specialized fields.

Recent analyses indicate that global (i.e., eustatic) sea level has risen at something close to $2 \mathrm{~mm}$ per year for at least the last century or so [Peltier and Tushingham, 1989; Trupin and Wahr, 1990;

\section{Copyright 1995 by the American Geophysical Union.}

Douglas, 1991], and probably at a much smaller rate for the previous several millennia [Flemming, 1978; Flemming and Webb, 1986; Kearney and Stevenson, 1991; Shennan and Woodworth, 1992; Varekamp et al., 1992]. In contrast, for the next century various authors plausibly argue that global sea level will rise at a much faster rate than at present because of global warming.

The Intergovernmental Panel on Climate Change (IPCC) report [Houghton et al., 1990] gives for the "business-as-usual" scenario of global warming an additional sea level change of $18 \mathrm{~cm}$ by 2030 and $44 \mathrm{~cm}$ by 2070. Church et al. [1991], in an important and thorough paper, calculate a rise of $35 \mathrm{~cm}$ by 2050 . Woodworth [1990] and Douglas [1992] have shown that such increases require an acceleration of sea level an order of magnitude greater (about $0.2 \mathrm{~mm}$ year $^{-2}$ ) than the negligible acceleration observed in the tide gauge record of the last 150 years. Observing and interpreting this small but highly significant acceleration of global sea level in a timely manner is a critical aspect of any climate monitoring program.

\section{Impacts of sea level rise}

Many fine reviews of the impact of sea level rise on coastal environments are available. Bird [1993], Warrick et al., [1993], and Nicholls and Leatherman [1994] emphasize and document the serious consequences of even a few mm per year increase of sea level. An excellent educational video presentation on the subject entitled Vanishing Lands, produced by the Laboratory for Coastal Research at the University of Maryland (College Park), vividly presents the impact of rising sea level in the Chesapeake Bay region of the United States.

Nicholls and Leatherman [op. cit.] summarize the physical effects of sea level rise into 5 categories. These are inundation of lowlying areas, erosion of beaches and bluffs, salt intrusion into aquifers and surface waters, higher water tables, and increased flooding and storm damage. All of these effects have important impacts, but I shall consider only the first two in this review because they have had and are continuing to have very dramatic impacts on coastal regions worldwide.

A rise of a few mm per year by the sea, although not threatening spectacular inundation of the sort described earlier, is still extremely important. Direct land loss of low lying areas can rapidly (decadal to centennial periods) damage or destroy coastal ecosystems. A good illustration of this occurs in the Chesapeake Bay. The average rate of relative sea level rise (RSLR) in this area has been approximately $3.5 \mathrm{~mm}$ per year during the twentieth century. This is about twice the global value of sea level rise. Regional subsidence, discussed below, is responsible for the increment over the global value. Downs et al. [1994] describe the widespread loss of the Bay's wetlands due to this increase of sea level. As just one example of the rapid and inexorable change that can occur, one third of the area of the Blackwater Wildlife Refuge area near Cambridge, Maryland was lost by inundation between 1938 and 1979.

This problem of land loss due to relative sea level rise is pervasive in coastal areas, and is aggravated by high levels of local subsidence. Another example is given by Day and Templett [1989]. They 
discuss the problem of land loss in the Mississippi delta, which has the largest rate of loss in the United States. There has been a net loss of wetlands of up to $100 \mathrm{~km}^{2}$ per year in the delta area during this century, and the situation will be aggravated if sea level rise increases by the amounts predicted to accompany global warming in the future.

In addition to inundation, long-term sea level rise can cause erosion and shoreline retreat by creating a sediment budget deficit. For a recent and thorough discussion of this effect, see Bird, [1993]. Simplifying considerably, for a sandy beach region the nearby seafloor profile takes on a shape primarily dependent on sand grain size, and secondarily on the energy of the incoming waves. In particular, the higher the energy of the waves, the greater the depth at which the wave action will disturb the depth profile, and the further offshore this limiting effect will occur. Thus the critical parameter for the nearshore depth profile is the ratio of the distance $\mathrm{L}$ (the active profile width) offshore at which the waves have an effect on the bottom, divided by the water depth $\mathrm{D}$ (depth of closure) at that distance. The dimensionless ratio L/D varies from about 50-200, with 100 being a typical value.

When sea level rises, the nearshore bottom profile changes in an attempt to gain a new equilibrium and restore the ratio $\mathrm{L} / \mathrm{D}$. This equilibrium is achieved by erosion of the shore by the amount of the sea level rise multiplied by the ratio $\mathrm{L} / \mathrm{D}$. (This relation of erosion, sea level rise, active profile width, and depth of closure is widely known as the Bruun rule [Bird, 1993], after its developer.) Since L/ $\mathrm{D}$ is usually of order 100 , the extent of horizontal beach erosion can be typically two orders of magnitude greater than the amount of the sea level rise. Thus while the up to $4 \mathrm{~mm}$ per year long term rise in the middle Atlantic region of the U.S. does not seem like much, a horizontal beach loss of 100 times this amount each year (that is, 4 meters in a decade) is significant indeed. Consider Virginia Beach, Virginia. This beach is now only 30-50 meters wide even after a major beach nourishment project.

It is clear from the above discussion that developing countries with large populations in or near deltas and other low-lying areas are especially vulnerable to future sea level rise. Nicholls and Leatherman [1994] have made estimates of the social and economic costs of sea level rise for many such nations. Their projections show that scores of millions of persons will be affected, and that direct economic losses and mitigation activities will pose serious financial burdens.

\section{Determining global sea level rise}

The most straightforward measurements of sea level are made by tide gauges. These instruments, usually placed on piers, measure the height of the sea relative to a nearby geodetic benchmark. A resurvey, commonly done annually, is made to determine if settling of the pier has occurred. New surveys are also needed if gauges are moved or replaced, so that sea level series taken at a site can be referred to a common datum in spite of disturbances of the instrument or its platform. Gauges for which such surveys have not been made are of no use for establishing long-term trends of sea level. See Spencer and Woodworth [1993] for an extended discussion.

Beyond such instrument platform effects, at any specific location the rate of relative sea level rise is modified by subsidence or emergence of the land in the area or region. This fact greatly complicates the problem of determining a value for the overall global rate of sea level change from tide gauge data.

The most ubiquitous source of regional submergence/emergence at tide gauge sites is the Post Glacial Rebound (PGR) that continues from the last deglaciation. It is manifest over the entire planet, not just at locations ice-covered at the last glacial maximum. Vertical crustal movements due to PGR at most sites are of approximately the same magnitude as the global (eustatic) rise. Peltier and Tushingham [1989] provide an excellent short summary of their ICE3G model for PGR, and a particularly clear treatment of the relevance of PGR to the sea level problem. An exhaustive treatment of PGR and the basis of the ICE-3G model is found in Tushingham and Peltier [1991]. A general overview of the phenomenon of PGR can be found in Lambeck [1991].

As particular examples of the effect of PGR, consider Baltimore, Maryland, and Stockholm, Sweden. The long-term (order 100 years) sea level rise of approximately $3.5 \mathrm{~mm}$ per year at Baltimore (and everywhere else in the Chesapeake region) is about twice the global rate because of subsidence due to the peripheral bulge collapse from the last deglaciation [Tushingham and Peltier, 1991]. In contrast, sea level at Stockholm falls by about $4 \mathrm{~mm}$ per year as land in the region continues to emerge in response to the disappearance of the ice there during the last deglaciation. It is clear that the effect of sea level change in the Baltic is very different than in the Chesapeake Bay. In general, however, falling sea levels from land emergence only occur at places deeply ice covered at the start of the last deglaciation 18,000 years ago. For most of the world's coastal population, sea level rise remains the practical issue.

It is obvious that any attempt at estimating global sea level rise from tide gauge data must take PGR into account, as well as other vertical crustal movements. As we shall see below, the nearly score of estimates published in the last few decades can be separated into distinct groups based on how PGR and other vertical crustal movements were considered.

Estimates of the rate of global sea level rise determined from tide gauge records have been summarized by Gornitz [1994] in a comprehensive and valuable review paper. The range of published estimates based on tide gauge data is about 1 to $3 \mathrm{~mm}$ per year. The data used for these estimates were supplied to investigators by the Permanent Service for Mean Sea Level (PSMSL) [Spencer and Woodworth, 1993], so that differences of estimates reflect the authors' approach to the problem, and not the data.

Of estimates made prior to 1989 , all but one were less than 1.5 $\mathrm{mm}$ per year. After eliminating the extreme value, both the mean and median of the 12 remaining values quoted by Gornitz [1994] are $1.2 \mathrm{~mm}$ per year. Since 1989 , the five new estimates published have been rather larger, also with a single exception. After eliminating that extreme value, the mean value of the recent estimates is 1.9 mm per year, and the median, 1.75. As Gornitz [1994] has noted, the recent estimates are different from the prior ones in that they have accounted for PGR. Thus Peltier and Tushingham [1989, 1991], Trupin and Wahr, [1990]; Wahr and Trupin, [1990]; and Douglas, [1991] all explicitly corrected their estimates of sea level trend for isostatic adjustment at the tide gauge sites. However, the PGR values used by these authors were in fact all computed by Peltier and his colleagues, so it could be argued that the agreement of the recent papers is fortuitous. The estimate of Nakiboglu and Lambeck [1991] also allowed for glacial rebound, but by an ad hoc method, and resulted in an estimate of eustatic rise (1.15 mm per year) more in line with earlier values.

What are we to make of this? Unfortunately, there are complicating factors beyond the issue of PGR, and published results reflect a lack of consensus as to how to deal with them as well. In addition to whether or not PGR was explicitly modeled, differences between analyses include data record length, tide gauge station selection criteria, and analysis method. The inability of investigators to arrive at a consensus concerning the rate of global sea level rise, or even how 
to approach the problem, has led some authors to conclude that global sea level rise cannot be measured at all. Barnett [1984] states that "....it is not possible to uniquely determine either a global rate of change of sea level or even the average rate of change associated with the existing inadequate data set." Emery and Aubrey [1991] state that (p. 176) "At present, we cannot discover a statistically reliable rate for eustatic rise of sea level alone..." Pirazzoli [1993] is the most pessimistic, declaring that "...the determination of a single sea-level curve of global applicability is an illusory task."

However, the situation for determining eustatic sea level rise may not be quite as hopeless as indicated by these authors. I shall argue in what follows that the differing estimates among authors arises (in addition to how PGR was treated) largely from the use of tide gauge records of inadequate length, and from use of sea level series from sites that suffer large vertical movements because of their proximity to convergent tectonic plate boundaries. In addition, completeness of record plays a very large role. The available long records show that sea level cannot be regarded as a stationary time series; large, unpredictable fluctuations that persist over decades are commonplace [Douglas, 1992]. These fluctuations severely compromise the use of records with large gaps for estimation of a meaningful or accurate value of long-term sea level rise.

The issue of record length has received some attention by authors who have made estimates of global sea level rise. Barnett [1984] selected for his study "Only stations that had 30 or more years of data..." Emery and Aubrey [1991], in Figure 39 on p. 83 of their book, present the confidence factors (from a t-test) that the estimated sea level trend for tide gauge records is within $1 \mathrm{~mm}$ per year of the true sea level trend. The figure shows a remarkable coherence of results for sea level records longer than 40-50 years. Inexplicably, they go on to consider records as short as 20 years to be adequate to suppress true sea level fluctuations, and thus reveal vertical crustal movements. Gornitz [1994] also states that "A time series of at least 20 years, and preferably longer, is needed..." The most extreme example of the use of short records was that of Nakiboglu and Lambeck [1991], who used 655 stations with record lengths as short as 10 years.

In fact, short (a few decades) tide gauge records are of no use whatsoever for determining an underlying long-term global trend, because of low-frequency fluctuations of sea level. Pugh [1987] on p. 320 gives a compelling graphical example of the problem for 10 year records. He demonstrates that 10 -year trends at a site can have different signs, depending on the time interval chosen. Douglas [1991] extended the approach used on 10 year records by Pugh [1987] to 30 year intervals. For San Francisco, the longest continuous record (140 years) in the U.S., he found that 30 year trends computed anywhere in the entire series varied from -2 to $+5 \mathrm{~mm}$ per year. Since the low frequency spectral content of the San Francisco record is in no way unusual, his analysis established the inadequacy of even $\mathbf{3 0}$ year records.

Sturges [1987] also pointed out the existence of interdecadal and longer fluctuations that can markedly influence estimated sea level trends. Finally, Roemmich [NRC, 1990, and in a preprint circulated for a number of years previously] in his analysis of sea level and hydrographic records at Bermuda and Charleston, S.C., showed that coastal and relatively nearby mid-ocean sea level trends can differ markedly over several decades. He concluded from his analysis that 50 year records of sea level and dynamic height are needed to understand the sea level fluctuations at a site.

Other quantitative analyses of the role of record length on estimated values of sea level have been made by Peltier and Tushingham [1989], and Douglas [1992]. Peltier and Tushingham [op. cit.] argued that for their selection of tide gauge records, the best balance between number of stations and spatial coverage was achieved at record lengths of 40-50 years. Douglas [1992] investigated the role of record length by computing the trend and acceleration for all sea level records longer than 10 years available from the Permanent Service for Mean Sea Level [Spencer and Woodworth, 1993]. The acceleration estimate is just a measure of the ability of a quadratic function to absorb the low-frequency component of each series. Figure 1, taken from Douglas [1992], shows that the low-frequency variations of sea level dominate the estimate of acceleration for records shorter than about 50 years. This result is entirely consistent with a straightforward interpretation of Emery and Aubrey's [1991] Figure 39. It is interesting that no obvious reason exists for why the coherence of trends and accelerations so strikingly increases for records longer than 50 years. This matter certainly deserves further investigation.

The conclusion that can be drawn from all of this is that 50 years is the absolute minimum sea level record length that should be considered in an analysis of global sea level rise or acceleration from tide gauge data alone. Fortunately, more long records are becoming available in many parts of the world because of the large number of tide gauges installed in the years following World War II. In addition, we shall see below that it may be possible to compute from other data much of the troublesome interdecadal sea level "noise", and eliminate it from the signal. The next 10 years should see much progress in the problem of separating vertical crustal movements at tide gauge locations from interdecadal fluctuations of sea level.

There are other factors affecting estimates of global sea level rise beyond record length. Statistically significant disagreements remain even among those studies that use only long time series. This has probably occurred because many long sea level series are contaminated by local crustal movements and/or data problems. Unfortunately, most of these tainted records have been used in published investigations.

One of the most striking examples of an unsuitable long sea level series is that of Seattle, Washington. The record of sea level there is continuous since 1899 . There are a number of other tide gauges in the immediate area, and geodesists have made good use of the highly discordant differential sea level trends in this region of converging tectonic plate boundaries to monitor vertical crustal movements. Obviously, a tide gauge record cannot serve both geodesy and global sea level analysis simultaneously. In this particular case, geodesy is the appropriate application. This is so because the low frequency periodic variations of sea level are practically the same at all of the sites due to the small size of the region.

Douglas [1991] identified other unsuitable long tide gauge records, including Manila (Philippines), Tonoura (Japan), Bombay (India), and others. He did find a total of 23 long (60 years minimum, 76 years average) records in 10 oceanographic regions, free of obvious tectonic effects and severe data gaps or defects. After correction for glacial rebound using the model results of Peltier and Tushingham [1989], the trends for these 10 regions averaged 1.8 $\mathrm{mm}$ per year with a root-mean-square ( $\mathrm{rms}$ ) variation about this mean of only $0.3 \mathrm{~mm}$ per year.

Finally, the question of distribution of tide gauge stations over the sphere must be addressed. Groger and Plag [1993] and others have rightly made much of this matter, but have failed to consider a critical factor; the longer the period of signal variation, the greater the spatial extent of that signal. Thus very long records do not require the coverage needed by shorter ones to establish a value for global change. On the scale of the era of the continuously recording tide gauge (about 150 years), Douglas [1991, 1992] has shown that widely separated tide gauge records show very consistent trends and (lack of) acceleration. Woodworth [1990] also observed the latter. 


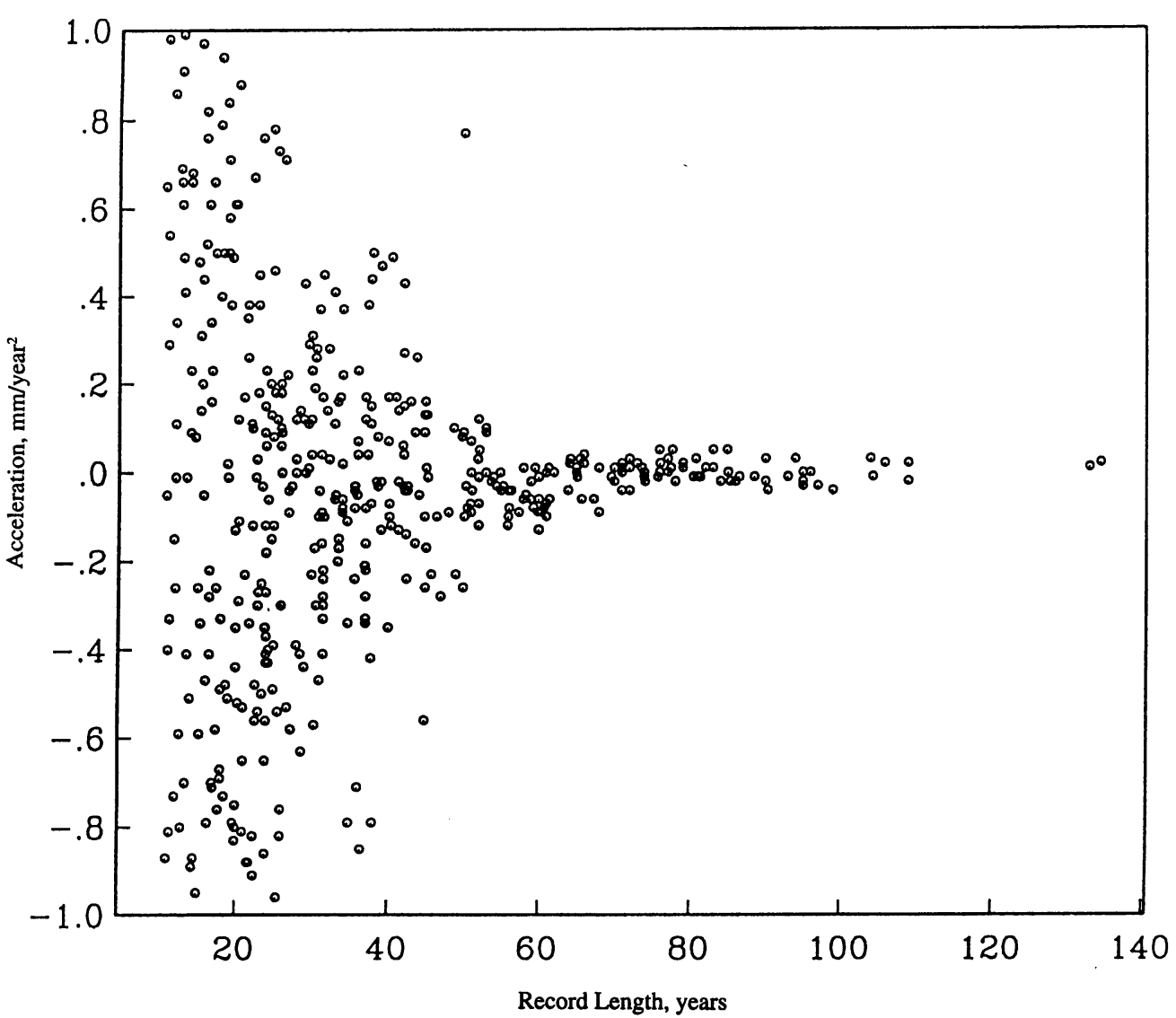

Figure 1. Apparent accelerations of sea level for records $>10$ years in length. Low-frequency variations of sea level heavily corrupt the computation of an acceleration parameter for records less than about 50 years long. From Douglas (1992).

Thus on the 100 year temporal scale, the lack of uniform global coverage appears to be much less important than usually supposed.

Assuming now that an average value of global sea level rise can be, and has been, determined for about the last 100-150 years, the next consideration is whether or not this value has undergone significant change over that time. Fortunately, determining acceleration of sea level change is less formidable than the linear problem, at least in regard to PGR and tectonic plate boundary effects. The reason is that PGR is linear over the tide gauge record, as are vertical crustal movements at plate boundary locations with long earthquake recurrence times. Thus both of these effects drop out in the calculation of acceleration. Woodworth [1990], and Gornitz and Solow [1991] have found weak evidence of acceleration in long European records, but no conclusive evidence of a global acceleration of sea level. Douglas [1992] carried out a systematic global analysis of sea level acceleration, and arrived at a similar result that no acceleration of global sea level has occurred over the last 150 years that is statistically significantly different from zero at the $95 \%$ confidence level. More important, all three of these authors have bounded any acceleration that might have occurred in the last 150 years at an order of magnitude or more less than that predicted to accompany global warming in the future [Houghton et al., 1990].

\section{Sea level rise during recent millennia}

There have been documented long-term changes of climate in the last several millennia comparable in magnitude to what might occur in the near future. Thus the question arises as to how the current (i.e., over the last $100+$ years) rate of sea level rise compares to that over the previous few millennia. This is an important issue; determining the past response of sea level to climate change could provide critical insights as to what might happen in the future.

There is a convincing body of evidence that the sea level rise value of the last $100+$ years has not pertained to the last 2 millennia. Flemming [1978], and Flemming and Webb [1986], report on the results of examining hundreds of coastal archeological sites in the Mediterranean area. In the latter paper it is noted that the average of detailed studies published since 1969 give for the eustatic change of sea level in the Mediterranean about $0.4 \mathrm{~m}$ for the last 2000 years, or $0.2 \mathrm{~mm}$ per year. The effect of PGR in the area is small and variable, according to the results of Tushingham and Peltier [1991], so that there is some confidence in the conclusion that the modern rate of eustatic sea level rise approaching $2 \mathrm{~mm}$ per year is a relatively recent development. In other words, the present-day elevation of Mediterranean archeological sites in relation to sea level is grossly inconsistent with the notion of a near $2 \mathrm{~mm}$ per year rate of sea level rise maintained over the past 2000 years.

Flemming [1982] has also reported on vertical crustal movements and eustatic rise for the United Kingdom since the onset of the last deglaciation. His results there are consistent with those for the Mediterranean. Shennan and Woodworth [1992] have also considered tide gauge and geological data in a larger region consisting of the UK and the North Sea boundary. They concluded that the rate of sea level rise during the time of tide gauge measurements is about 1 $\mathrm{mm}$ per year higher in the area than during the late Holocene, further evidence that in the recent past (order $100+$ years) sea level is rising faster than in earlier millennia.

Additional evidence exists outside of Europe for a low rate of sea level rise in the last several thousand years. Varekamp et al. [1992] have dated marsh cores in Connecticut by several methods 
and obtained consistent results. They found an average value of about $1.1 \mathrm{~mm}$ per year for sea level rise in Connecticut for the last 1500 years. The ICE-3G model of Tushingham and Peltier [1991] gives for subsidence due to PGR in this area about $1.5 \mathrm{~mm}$ per year, implying a fall of eustatic sea level of $0.4 \mathrm{~mm}$ per year over the period. Given the uncertainties in both the PGR and their sea level estimates, this result should be regarded as evidence for an insignificant average eustatic change during the 1500 year interval.

Varekamp et al. [1992] did find significant periodic changes of sea level in their investigation, and concluded that their "...data show no unequivocal correlation between warm periods (on a decadal to centennial time-scale) and accelerated sea level rise." This is an obviously intriguing and challenging result which deserves more research, and verification at other sites.

The Chesapeake Bay provides yet more strong evidence that the average value of sea level rise was lower before the 19th century than since that time. Kearney and Stevenson [1990] studied marsh vertical accretion rates by independent (pollen and radionuclide) methods, and by reconstruction of land loss in the Bay since colonial times from historical records. They document that rates of sea level rise were relatively slow during the 17 th and 18 th centuries, and that the current rapid rate of sea level rise (about $3.5 \mathrm{~mm}$ per year) dates only from the early 19 th century. Prior to that sea level was apparently stable in the region, possibly, they remark, as a response to the Little Ice Age. They also speculate that groundwater withdrawal for commercial operations could have played a role in the late 19th century. However, the documented increased rise of sea level in the entire mid-Atlantic region over the historical tide gauge record does not require an appeal to land subsidence anthropogenic in origin.

\section{Global sea level rise as an indicator of climate change}

Sea level is obviously directly related to extremes of climate change. As a gross example, at the beginning of the last deglaciation 18,000 years ago sea level was everywhere about 100 meters lower than it is now. The more subtle question is, can we observe future small (fractional $\mathrm{mm}$ ) changes of sea level quickly enough, and also interpret them, to provide a useful index of smaller but important changes of climate?

Using estimates of eustatic sea level rise as an indicator of climate change faces the difficulty that sea level rise is an output combining many individual effects. Some of these effects can offset others, so that the exact response of global sea level to climate change remains somewhat uncertain. It is necessary to work out a hydrological and geophysical budget for the various contributors to local and global sea level change. For example, global warming will cause both expansion of the ocean and changes of circulation [Church et al., 1991]. In addition, the melting of small glaciers, while difficult to quantify, is also significant [Meier, 1984]. These two effects together can account for about one $\mathrm{mm}$ per year of sea level rise over the last century, assuming that a global warming of about 0.5 degree $C$ has occurred.

Contributions of the Greenland and Antarctic ice sheets can play a different role. In the case of Greenland, Zwally et al. [1989] claimed that satellite altimeter data showed a thickening of ice there from 1978-87 equivalent to a fall of sea level of a few tenths of a mm per year. If this scenario held true over an extended time, then a possible increase of eustatic sea level rise from global warming, for example from thermal expansion, could be offset by increased storage of water in the form of ice on Greenland because of increased precipitation there. Douglas et al. [1990] vigorously disputed the adequacy of the satellite altimeter data analysis technique used by
Zwally et al. [op. cit.], and further calculated that the alleged increase of ice thickness (about $20 \mathrm{~cm}$ per year) would have changed the angular momentum of the earth in a manner that was not in fact observed. Van der Veen [1993] has also disputed the Zwally et al. [1989] result on purely glaciological grounds. But the basic issue remains. If global warming causes increased precipitation at very high latitudes with concomitant storage of water in the form of ice, sea level rise due to thermal expansion of the ocean or melting of small glaciers could be offset to a greater or lesser extent.

One must also consider the matter of watẹr storage in artificial reservoirs that would otherwise have flowed into the oceans. Chao [1991] calculated that the increasing storage of water in both large and small above-ground reservoirs was equal to a fall of global sea level of $0.7 \mathrm{~mm}$ per year over the last 40 years. Since this figure must be added to the current eustatic rate to accurately reflect the real situation, an unexpectedly large source of water must be found to account for it. Sahagian, et al., [1994] found a smaller effect, but ignored the very large contribution of small reservoirs.

From these considerations it is clear that simply obtaining a value for global sea level rise in the past, or detecting an increase in the future, is not enough for sea level rise to serve as an unambiguous indicator of global climate change. Global sea level, whether observed to increase, stay the same, or decrease, must be analyzed and understood in terms of all of the factors that affect it for meaning to be attached to it.

\section{The future of sea level research}

The case has been argued in this paper that global sea level rise over the last $100-150$ years has averaged nearly $2 \mathrm{~mm}$ per year, with no evidence of acceleration, and that this value is possibly an order of magnitude greater than the average over the last two millennia. Assuming for the moment that the arguments have been convincing, what precisely is it that can be learned from these conclusions?

We have seen that it is difficult to interpret any value for global sea level rise because there are so many contributors to it. Ice accumulation at high latitudes, ocean thermal expansion and changes of circulation, melting of small glaciers, and water storage in large and small artificial reservoirs can offset one another to a greater or lesser extent. One must also account for the relative stability of sea level for the several millennia prior to 19th century, and the subsequent sudden (in historic terms) increased rate of rise beginning well before there was a significant increase of anthropogenic atmospheric greenhouse gases. Finally, the strongly-held and not totally implausible view that the global sea level rise value reported by recent authors is only an artifact resulting from coastal subsidence or poor data distribution, must be addressed. (I do not anticipate that this review will result in the sudden disappearance of those objections.) In spite of all of the publication activity over the last 20 years, it seems very clear that much remains to be accomplished in the area of sea level determinations and analyses. On a positive note, at least the questions that need to be answered are now well understood.

The prospects for rapid progress in resolving the controversies and issues in the matter of global sea level rise are excellent. The areas that need to be explored are mostly known, and new technologies offer solutions to many of the problems. Research into the problem of global sea level rise must in the future include at least the following elements, and perhaps others. These are recovery of old and unpublished data (sometimes called data archeology), monitoring of crustal movements and earth angular momentum, repeated observations of water column height, ocean modeling, artificial sources and sinks of water on land, retreat of small glaciers, satellite and other surveys of polar ice sheet elevation, and satellite altimetric determinations of global sea level. The length of this list cer- 
tainly underscores the interdisciplinary essence of research into global sea level.

In the matter of data archeology, Hannah [1990] and Maul and Martin [1993] have made important contributions. The former author has provided new, very long records in New Zealand, in the southern hemisphere where long records are sparse. The latter authors were able to construct a summary geodetic datum and connect several tide gauge sites at Key West, Florida. This extends the sea level record there to 1846 . Although not yielding a continuous record in the 19th century, and so not as strictly useful as the complete record at San Francisco that reaches to 1854 , the series was adequate to demonstrate that no significant acceleration of sea level occurred over the record. They estimated the value of relative sea level rise to be $1.9+/-0.1 \mathrm{~mm}$ per year, very much in line with estimates elsewhere in Florida. In addition, Maul and Martin [1993] found that this long record provides estimates of absolute sea level rise of 1.7$2.4 \mathrm{~mm}$ per year, depending on which recent correction for PGR that is applied. One can only hope that other old tide gauge records can be found and made available.

More sea level records over the last several millennia derived from dated sedimentary cores are also needed. There are enough historical records of climate change, particularly since the middle ages, to make comparisons of these records and sea level change a valuable activity for climate modelers. Those who would predict the future must first be able to explain the past.

The single most contentious issue concerning studies of global sea level rise has been the matter of vertical crustal movements. These definitely play a major role, and no reliable estimate of global sea level rise can be obtained without careful consideration of them. But for sea level records shorter than about 50 years, low frequency variations of sea level are an equally important source of geophysical noise. Both vertical crustal movements and water column density changes must be evaluated, and filtered from sea level series for rapid, accurate measurement of global sea level rise and acceleration.

Concerning vertical crustal movements, the technology required to observe them exists, and is reasonable in cost. Carter et al. [1989] describe a monitoring system that uses Very Long Baseline Interferometry (VLBI) [Carter et al., 1986] for establishment of a global absolute geodetic reference system to which tide gauge sites can be connected. Baker [1993] provides a good summary of the Carter et al. [1989] report, and Eden [1990] includes oceanographic and meteorological considerations.

Movements of individual tide gauge sites can be monitored with respect to the absolute global geodetic datum using Global Positioning System (GPS) receivers. The elements of this system are in place, and accuracy in the vertical direction of order $1 \mathrm{~cm}$ or better demonstrated [Carter et al., 1988]. Thus areas of unusual subsidence can be evaluated relatively quickly, and model results for vertical changes due to PGR can be tested in a few years time. A joint effort involving the National Ocean Service of NOAA, the NASA Goddard Space Flight Center, and the Laboratory for Coastal Research at the University of Maryland has been set up to monitor subsidence in the Chesapeake Bay region. Continuously operating receivers are operating at Solomons Island, Greenbelt, Annapolis, and Gaithersburg in Maryland. These are also observing simultaneously with receivers at Bermuda (an important sea level station), and at VLBI sites in Massachusetts and Florida. More stations will be added in the next few years, so that both local and regional scale vertical movements will be revealed. Since GPS receivers with the features needed for monitoring at the sub-cm level cost only about $\$ 20 \mathrm{~K}$, monitoring of tide gauge sites for vertical movements at a global network of locations is practical now.
It is also possible to monitor vertical crustal movements at certain sites by measuring changes of the force of gravity. Repeatability equivalent to height change of a few $\mathrm{mm}$ has been achieved in field operations [Klopping et al., 1991]. Thus GPS results for elevation change can be calibrated against measurements from absolute gravity meters.

The GPS has implications for global change research far beyond monitoring of vertical crustal movements. Mader and Lucas [1989], Brozena et al. [1993], and others have demonstrated that moving platforms such as airplanes can be navigated at the few-cm level of accuracy. Thus airborne laser profiling of small and large glaciers is practical. This technology also enables photogrammetric surveys of shorelines, ice floes, etc., to be made repeatedly and compared for changes without in situ geodetic control. GPS is also being used to supplement the global VLBI system for monitoring earth angular momentum. As noted earlier, changes in the distribution of water alter the angular momentum vector of the earth, both in angular velocity and direction. Angular momentum of the earth is a unique integrator over many effects and provides an important constraint for observational and model results.

The other factor that plagues determination of sea level rise is low-frequency "noise" from interdecadal water column density fluctuations. A solution to this problem is needed if an acceleration of sea level is to be detected soon enough to be useful as an indicator of climate change [Woodworth, 1990; Douglas, 1992]. Roemmich [in NRC, 1990] showed that the decimeter-level interdecadal fluctuations of sea level at Bermuda were explained entirely by changes in dynamic height above $2000 \mathrm{~m}$. Roemmich [1992] was able to account for similar fluctuations in the ocean offshore of the southern half of California, at least in part, from upper ocean temperature variations. The dilemma for this approach is that there are very few sites whose water column properties are measured frequently over extended periods, as at Bermuda and now Hawaii.

Another approach taken by Sturges and Hong [1994] may provide an alternative solution for the sea level problem. They “...made a simple model of wind forcing of the Atlantic... and...find sea level variability...estimated this way in remarkably good agreement with observations..." Figure 2, taken from their paper, illustrates the efficacy of their approach. The interdecadal fluctuations of sea level are accurately modeled, and the removal of this "noise" will make it far easier to determine an underlying trend. Clearly, if crustal movements can be monitored with space geodetic techniques, and low frequency fluctuations of water column height measured or modeled even in part for a globally distributed set of sea level observing stations, the eustatic rise and any change in its rate can be observed relatively quickly. The extrapolation study in Woodworth [1990] indicates that an acceleration of sea level could be determined under these conditions very early in the next century.

Finally, satellite altimetry cannot be overlooked as a means of obtaining a direct, global measurement of sea level change. Wagner and Cheney [1992] examined altimeter data from the Seasat and Geosat oceanographic satellites and found that the principle errors to overcome for this application were those associated with the ionospheric and water vapor corrections, and absolute calibration of the altimeter, including the orbit. All of these matters have been explicitly addressed by the TOPEX/Poseidon oceanographic satellite which began its 5-year mission in 1992 [ $F u$ et al., 1994]. The TOPEX/ Poseidon satellite uses a dual frequency altimeter to determine the ionospheric correction, a water vapor radiometer for direct measurement of the precipitable water in the path of the altimeter beam, and advanced Global Positioning System (GPS), laser, and DORIS dual frequency doppler tracking systems for orbit determination [ $\mathrm{Fu}$ et al., 1994]. Cheney et al. [1994] conclude that TOPEX/Poseidon 


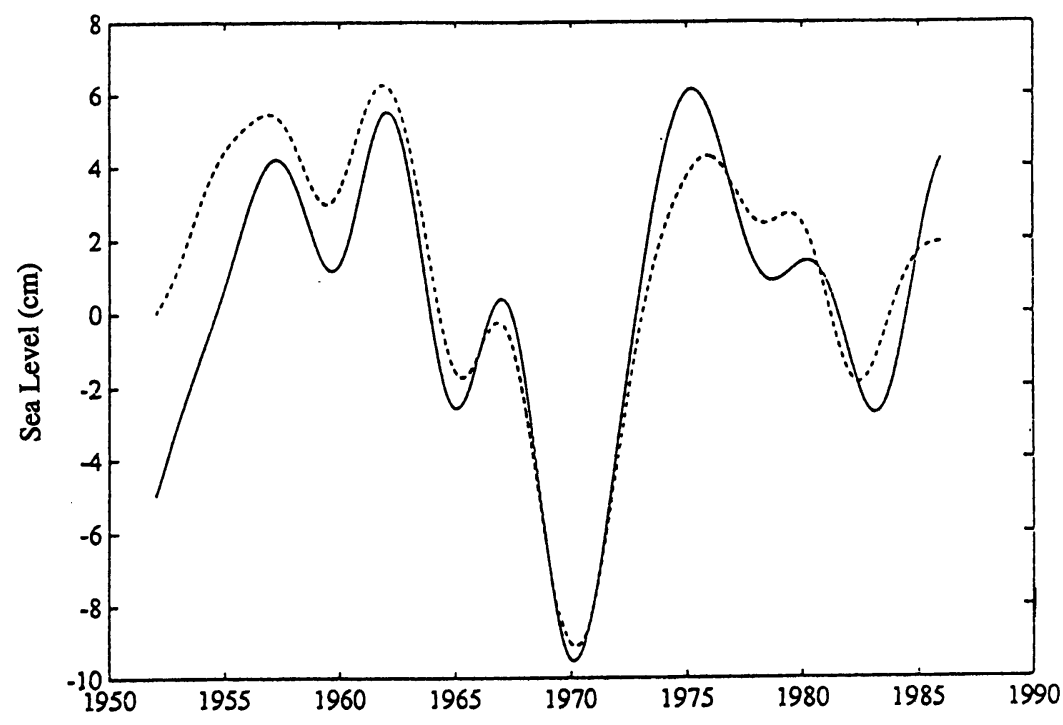

Figure 2. Comparison between observed and computed sea level fluctuations for Bermuda. The observed sea level record, adjusted to constant atmospheric pressure, is shown by the solid curve. From Sturges and Hong (1994).

data are accurate at the level of $2 \mathrm{~cm}$ for monthly mean changes on scales of a few hundred $\mathrm{km}$, and by inference far more accurate on a global, annual scale. In support of this view, Wagner et al., [1994] report a robust determination of global sea level rise over two years of the TOPEX/Poseidon mission of $5 \mathrm{~mm}$ per year, which when corrected for instrument drift [Hayne et al., 1994] gives about $3 \mathrm{~mm}$ per year. This satellite altimeter result is not far from recent estimates of global sea level rise for the last $100+$ years derived from tide gauge data. The agreement could be fortuitous, but the result is interesting, and demonstrates the potential of the method.

Thus it appears that the problem of obtaining an accurate estimate of global sea level rise and acceleration is tractable. If the supporting measurements of ice volume, water storage, and earth angular momentum are also continued and expanded, the scientific problem of interpreting the sea level results will also become tractable, and the entire field of global change will greatly benefit.

\section{References}

Baker, T. F., Absolute sea level measurements, climate change and vertical crustal movements, Global and Planetary Change, 8, 145-149, 1993.

Barnett, T. P., The estimation of "global" sea level change: a problem of uniqueness, J. Geophys. Res., 89, no. c5, 7980-7988, 1984.

Bird, E. C. F., Submerging Coasts, John Wiley and Sons, 1993.

Brozena, J. M. Peters, and R. Forsberg, Airborne measurements of sea surface height, Geophys. Res. Let., 20, no. 9, 875, 1993.

Carter, W. E., D. G. Aubrey, T. Baker, C. Boucher, C. LeProvost, D. Pugh, W. Peltier, M. Zumberge, R. Rapp, B. Schutz, K. Emery, and D. Enfield, Geodetic fixing of tide gauge bench marks, in Woods Hole Oceanographic Institution Technical Report.WHOI89-31, 1989.

Carter, W. E., A. Nothnagel, G. D. Nicolson, H. Schuh, and J. Campbell, IRIS-S: extending geodetic VLBI observations to the southern hemisphere, J. Geophys. Res., 93, 14947-14953, 1988.

Carter, W. E., and D. S. Robertson, Studying the earth by very long baseline interferometry, Scientific American, 255, no. 5, 44-52, 1986.

Chao, B. F., Man, water, and global sea level, EOS Trans. AGU 72, no. $45,492,1991$.

Cheney, R. E., L. Miller, R. A. Agreen, N. S. Doyle, and J. L.
Lillibridge, TOPEX/Poseidon: The 2-cm solution, J. Geophys. Res., in press, 1994.

Chui, G., "The search for sea level", San Jose Mercury News, sec. C, p. 1, August 13, 1991.

Church, J. A., J. S. Godfrey, D. R. Jacket, T. J. MacDougal, A model of sea level rise caused by ocean thermal expansion, J. Climate, 4, no. 4, 438-456, 1991.

Dean, C., "Coast experts debate tide gauges' findings", New York Times, sec. C, p.1, August 27, 1991.

Douglas, B. C., R. E. Cheney, L. Miller, W. E. Carter, and D. S. Robertson, Greenland ice sheet; is it growing or shrinking? Science 248, 288, 1990.

Douglas, B. C., Global sea level rise, J. Geophys. Res., 96(C4), 6981-6992, 1991.

Douglas, B. C., Global sea level acceleration, J. Geophys. Res., 97(C8), 12,699-12,706, 1992.

Downs, L. L., R. J. Nicholls, S. P. Leatherman, and J. Hautzenroder, Historic evolution of a marsh island: Bloodsworth Island, Maryland, J. Coastal Res., in press, 1994.

Eden, H. F. (Ed.), Towards an Integrated system for Measuring Long Term Changes in Global Sea Level, Joint Oceanographic Institutions, Inc., Washington, D.C., May, 1990.

Emery, K. O., and D. G. Aubrey, Sea Levels, Land Levels, and Tide Gauges, Springer-Verlag, 1991.

Flemming, N. C., Holocene eustatic changes and coastal tectonics in the northeast Mediterranean; implications for models of crustal consumption, Phil. Trans. Royal Soc. London, 289, no. 1362, 405-458, 1978.

Flemming, N. C., Multiple regression analysis of earth movements and eustatic sea-level change in the United Kingdom in the last 9000 years, Proc. Geol. Assn., 93, no. 1, 113-125, 1982.

Flemming, N. C., and C. O. Webb, Tectonic and eustatic coastal changes during the last 10,000 years derived from archeological data, Z. Geomorph. N.F., Suppl.-Bd. 62, 1-29, Berlin, December, 1986.

Fu, L. L., E. Christensen, M. Lefebvre, and Y. Menard, TOPEX/ POSEIDON mission overview, J. Geophys. Res., in press, 1994.

Gornitz, V., and L. Seeber, Vertical crustal movements along the east coast, North America, from historic and late Holocene sea level data, Tectonophysics 178, 1990.

Gornitz, V. and A. Solow, Observations of long-term tide-gauge 
records for indicators of accelerated sea level rise, in Greenhouse Gas-Induced Climatic change: A Critical Appraisal of Simulations and Observations, edited by M. E. Schlesinger, pp. 347367, Elsevier, Amsterdam, 1991.

Gornitz, V., Mean sea level changes in the recent past, in Climate and sea level change; Observations, projections, and implications, edited by R. A. Warrick, E. M. Barrow, and T. M.L. Wigley, Cambridge U. Press, 1993.

Gornitz, V., Sea level rise: a review of recent past and near-future trends, Earth Surface Processes and Trends, in press, 1994.

Groger, M., and H. P. Plag, Estimations of a global sea level trend: limitations from the structure of the PSMSL global sea level data set, Global and Planetary Change, 8, 161-179, 1993.

Hannah, J., Analysis of mean sea level data from New Zealand for the period 1899-1988, J. Geophys. Res., 95, no. B8, 1990.

Hayne, G. S., D. W. Hancock III, and C. L. Purdy, TOPEX altimeter range stability estimates from calibration mode data, TOPEX/ POSEIDON Research News, Issue 3, 18-27, Jet Propulsion Lab, October, 1994.

Houghton, J. T., G. J. Jenkins, and J. J. Ephraums (Eds.), Climatic Change; the IPCC Scientific Assessment, Cambridge U. Press, Cambridge, England 1990.

Kearney, M.S., and J. C. Stevenson, Island land loss and marsh vertical accretion rate evidence for historical sea-level changes in Chesapeake Bay, J. Coastal Res. 7, no. 2, 403-415, 1991.

Klopping, F., G. Peter, D. S. Robertson, K. A. Berstis, R. E. Moose, and W. E. Carter, Improvements in absolute gravity observations, J. Geophys. Res., 96, no. b5, 8295-8303, 1991.

Lambeck, K., Glacial rebound, sea level change, and mantle viscosity, Q. J. Roy. Astron. Soc., 31, 1-30, 1990.

Leatherman, S. P., Impact of accelerated sea level rise on beaches and coastal wetlands, in Global Climate Change Linkages, pp. 43-56, Elsevier, 1989.

Leatherman, S. P., Modeling shore response to sea level rise on sedimentary coasts, Progress in Physical Geography, 14, 447-464, 1991.

Leatherman, S. P., Coastal land loss in the Chesapeake Bay region: an historical analogy approach to global climate analysis and response, in The Regions and Global Warming: Impacts and Response Strategies, edited by J. Schmandt, pp.17-27, Oxford U. Press, 1992.

Maul, G. A., and D. M. Martin, Sea level rise at Key West, Florida, 1846-1992: america's longest instrument record?, Geophys. Res. Letters, 20, no. 18, 1955-1958, 1993.

Meier, M. F., The contribution of small glaciers to global sea level, Science, 226, 1418-21, 1984.

Nakiboglu, S. M., and K. Lambeck, Secular sea level change, in Glacial Isostasy, Sea Level, and Mantle Rheology, edited by R.

Sabatini, K. Lambeck, and E. Boschi, pp. 237-258, Kluwer Academic Publ., Dordrecht, 1991.

National Research Council (NRC) report on Sea Level Change, National Academy Press, Washington, DC, 1990.

Nicholls, R. J., and S. P. Leatherman, Global sea-level rise, in As Climate Changes: Potential Impacts and Implications, edited by K. Strzepek and J. B. Smith, Cambridge University Press, Cambridge, in press, 1994.

Peltier, W. R., and A. M. Tushingham, Global sea level rise and the greenhouse effect: might they be connected?, Science 244 , no. 4906, 806-810, 1989.

Pirazzoli, P. A., Global sea level changes and their measurement, Global Planet Change, 8, 135-148, 1993.

Pugh, D. T., Tides, Surges, and Mean Sea Level, John Wiley and Sons, 1987.

Roemmich, D., Ocean warming and sea level rise along the southwest U.S. coast, Science, 257, 373-375, 1992.

Sahagian, D., Schwartz, F. W., and D. K. Jacobs, Direct anthropogenic contributions to sea level rise in the Twentieth Century, Nature, 367, no. 6458, 1994.

Shennan, I., and P. L. Woodworth, A comparison of late Holocene and twentieth-century sea-level trends from the UK and North Sea region, Geophys. J. Int., 109, no. 1, 96-105, 1992.

Spencer, N. E., and P. L. Woodworth, Data Holdings of the Permanent Service for Mean Sea Level, Bidston, Birkenhead: Permanent Service for Mean Sea Level, November, 1993.

Sturges, W. E., Large-scale coherence of sea level at very low frequencies, J. Phys. Oceanogr. 17, 2084-2094, 1987.

Sturges, W. E., and B. G. Hong, Wind forcing of the Atlantic thermocline along $32 \mathrm{deg}$. north at low frequencies, J. Phys. Oceanogr., in press, 1994

Trupin, A., and J.Wahr, Spectroscopic analysis of global tide gauge sea level data, Geophys. J. Int., 100, 441-453, 1990.

Tushingham, A. M., and W. R. Peltier, ICE-3G: A new global model of late Pleistocene deglaciation based upon geophysical predictions of post glacial relative sea level change, J. Geophys. Res., 96, 4497-4523, 1991.

Van Der Veen, C. J., Interpretation of short-term ice-sheet elevation changes inferred from satellite altimetry, Climatic Change 23, 383-405, 1993.

Varekamp, J. C., E. Thomas, and O. Van de Plassche, Relative sea level rise and climate change over the last 1500 years, Terra Nova, 4, 293-304, 1992.

Wagner, C. A. and R. E. Cheney, Global sea level change from satellite altimetry, J. Geophys. Res., 97, (C10), 15,607-15,615, 1992.

Wagner, C.A., R.Cheney, L. Miller, C. K. Tai, N. Doyle, and J. Lillibrid ge, Global sea level change from altimetry, EOS Trans. $A G U$, p.56, November 1, 1994.

Warrick, R. A. Barrow, E. M., and T. M. L. Wigley (Eds.), Climate and sea level change: observations, projections, and implications, Cambridge U. Press, Cambridge, 1993.

Woodworth, P. L., A search for accelerations in records of European mean sea level, International J. Climatology, 10, 129-143, 1990.

Woodworth, P. L., Pugh, D. T., DeRonde, J. G., R. G. Warrick, and J. Hannah, (Eds.), Sea Level Changes: Determination and Effects, American Geophysical Union, Washington, D.C., 1992.

Woodworth, P. L., A review of recent sea level research, Oceanogr. Mar. Biol. Annu. Rev. 31, 87-109, 1993.

Zwally, H. J., Brenner, A. C., Major, A. J., Bindschadler, R. A., and J. G. Marsh, Growth of Greenland ice sheet; measurement, Science, 246, 1587-1589, 1989.

B. C. Douglas, National Oceanic and Atmospheric Administration, National Oceanographic Data Center, 1825 Connecticut Avenue, NW, Washington, DC 20235. (e-mail: bdouglas@nodc.noaa.gov).

(Received June 10, 1994; revised November 14, 1994; accepted December 12, 1994) 